\title{
Measuring the Solid Phase Fractionation of Lead in Urban and Rural Soils using a combination of Geochemical Survey data and Chemical Extractions
}

\author{
Mark Cave $^{1 凶}$, Joanna Wragg ${ }^{1}$, Charles Gowing ${ }^{1}$ and Amanda Gardner ${ }^{1}$ \\ ${ }^{1}$ British Geological Survey, Environmental Science Centre, Keyworth Nottingham N12 5GG \\ $\otimes_{\text {Mark Cave }}$ \\ Email:mrca@bgs.ac.uk
}

\begin{abstract}
The study used 276 urban soils and 447 rural soils collected from in and around the UK town of Northampton and focussed on the fractionation of $\mathrm{Pb}$. The $\mathrm{Pb}$ fractionation obtained from total element data was compared to the fractionation of $\mathrm{Pb}$ in a subset of 10 urban soils obtained using a sequential extraction method. The fractionation of the $\mathrm{Pb}$ from the total element data and from the sequential extractions was estimated using a self-modelling mixture resolution statistical model. The bioaccessibility of $\mathrm{Pb}$ in a subset of 50 of the urban soils, as measured using the Unified BARGE Method, was shown to be quantitatively linked with $\mathrm{Pb}$ fractionation from both the total element and the sequential extraction data. Three intrinsic soil components from the regional total element data model and one physico-chemical component from the sequential extraction data model were identified as the sources of bioaccessible $\mathrm{Pb}$. The source of bioaccessible $\mathrm{Pb}$ in both rural and urban soils was tentatively identified as a fine grained pyromorphite mineral.
\end{abstract}

\section{Keywords}

$\mathrm{Pb}$, fractionation, soil, bioaccessibility, chemometrics, urban

\section{Introduction}

Mobilisation of potentially harmful elements (PHE) in the terrestrial environment has been occurring for millions of years from the natural weathering of the parent rocks. Anthropogenic activities have added to this through various activities such as metalliferous mining and smelting, fossil fuel combustion, traffic-related emissions, waste disposal, agricultural practices and the addition of horticultural materials as well as warfare and military contributions. Whilst the presence of PHE in the surface environment poses a hazard to human and animal health it does not become a risk until the PHE can be mobilised from their sources and reach a receptor. A relatively simple and well-adopted method to assess trace element pools of differential relative lability in soils is the use of single and sequential extraction procedures (Abollino et al. 2011; Bacon and Davidson 2008). They provide information on the mobility and availability of metals and other elements, meanwhile identifying their potential negative impact through their release into other environmental compartments, including human ingestion.

Despite the relative simplicity of these extraction procedures, it is not feasible to apply them to large geochemical data sets which may consist of hundreds or even thousands of samples which represent regional or national scale studies (Johnson et al. 2005).

In a study of the bioaccessibility of As in soil, Wragg et al. ( 2007) have suggested that the fractionation of PHE in soils can be assessed by assuming that soils from a particular region are made up from different chemical inputs e.g. underlying geology, plant materials, anthropogenic inputs from both diffuse and point source pollution and agricultural inputs. They applied a chemometric mixture resolution algorithm to total major and trace element data from a small scale study of 20 soil samples to identify the chemical composition and amount of these Intrinsic Soils Components (ISC) as well as the distribution of As between the ISCs.

The objective of this study is to apply a similar ISC chemometric identification procedure to total chemical analysis data from a regional scale set of 723 soil samples collected as part of the British Geological Survey GBASE systematic geochemical survey of soils, stream sediments and surface waters (Johnson et al. 2005). The 
soils consist of 276 urban soils and 447 rural soils collected from in and around the UK town of Northampton. In this study the focus is on the fractionation of $\mathrm{Pb}$ in the Northampton area. The ISC $\mathrm{Pb}$ fractionation data was compared to the fractionation of $\mathrm{Pb}$ in a subset of 10 urban soils obtained using the CISED sequential extraction test (Cave et al. 2004) and to the bioaccessibility of $\mathrm{Pb}$ in a subset of 50 of the urban soils measured using the Unified BARGE Method (UBM) (Denys et al. 2012).

The overall aim of the study is to combine the information from the regional scale ISC identification, the urban CISED extraction test and the $\mathrm{Pb}$ bioaccessibility testing to provide an overview of the solid phase fractionation of $\mathrm{Pb}$ in the soils of the Northampton area and its relative lability as measured by UBM. The outcomes will be used as an evaluation of a new approach to interpreting geochemical survey data and, more specifically, provide data on the behaviour of $\mathrm{Pb}$ in soils in rural and urban environments with specific reference to human exposure.

\section{Materials and Methods}

\section{Site description}

A detailed description of Northampton and its geology is given in a recent study of the bioaccessibility of As in soils in the town (Cave et al. 2013). Briefly, Northampton is a large market town in central England (Fig. 1), with a population of ca. 200,000, located on Jurassic ironstones (Northampton Sand Formation and Marlstone Rock). The industrial development of the county of Northamptonshire, including the growth of Northampton, was supported by open cast quarrying of the abundant iron ore in the middle of the 19th century. There were also considerable leather currying and tanning works, breweries, iron foundries, and brick and tile works distributed across the area. It is, however, the shoemaking industry, which was very large, at one time employing $75 \%$ of the population of the county that is more often associated with Northampton. The surrounding area is quite rural, dominated by agriculture, but there is a large motorway (M1) running through the sampling area (Fig.1).
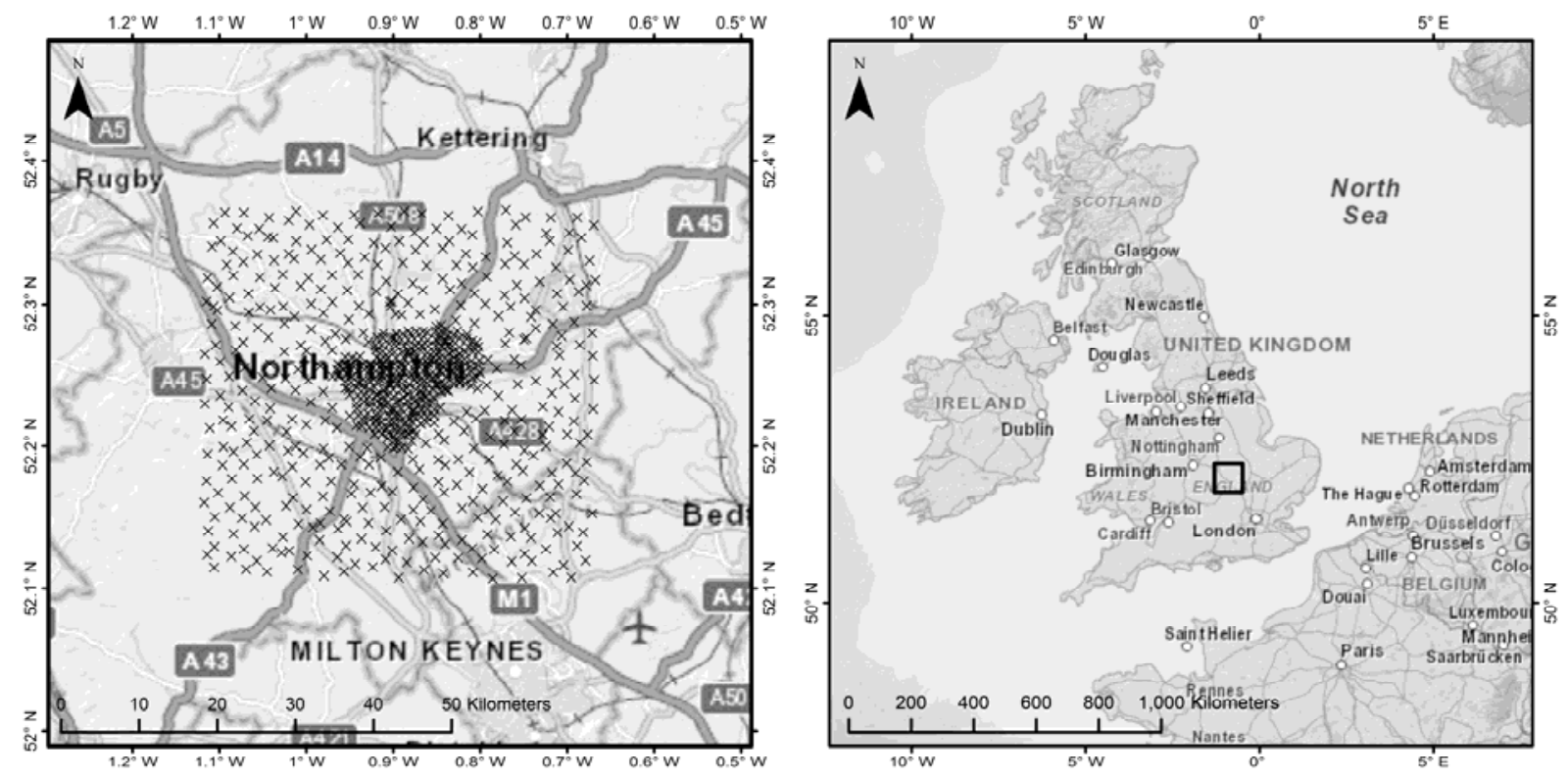

Fig. 1 location of the urban and rural samples in and around Northampton. The left hand map shows the sampling locations at a local scale and the right hand map shows the location of the sampling area on a national scale.

A comparison of the total $\mathrm{Pb}$ content of the soils from the urban and rural samples is shown in a boxplot in Fig. 2. Unsurprisingly, the $\mathrm{Pb}$ concentrations in the urban environment are generally higher than in the rural sites (median urban $55.9 \mathrm{mg} \mathrm{kg}^{-1}$, median rural $35.9 \mathrm{mg} \mathrm{kg}^{-1}$ ). All of the urban soils are below the normal background concentration (NBC) of $820 \mathrm{mg} \mathrm{kg}^{-1}$ for the Urban Domain for English soils and only four of the samples that 
came from the rural sampling campaign are above the Principal Domain NBC of $180 \mathrm{mg} \mathrm{kg}^{-1}$ (Ander et al. 2013).

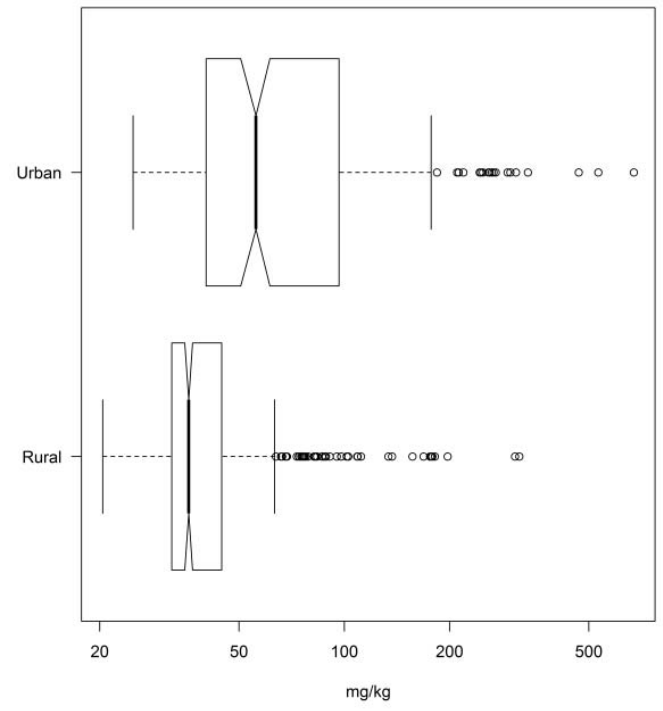

Fig. 2 Box and whisker plots of the $\mathrm{Pb}$ concentrations in the urban and rural soils in and around Northampton

\section{Sample collection, preparation and determination of total concentrations}

The soil samples were collected according to the BGS Geochemical Baseline Survey of the Environment (GBASE) sampling procedure (Flight and Scheib 2011). Collection was carried out on a $500 \mathrm{~m}$ grid at a density of 4 per $\mathrm{km}^{2}$ in open ground for the urban soils and 1 every $2 \mathrm{~km}^{2}$ for the rural samples. These are collected using a hand held dutch soil auger where each sample was comprised of a composite of 5 sub-samples collected from a $5-20 \mathrm{~cm}$ depth at the centre and four corners of a $20 \mathrm{~m}$ square. The total element concentration of ca. 40 elements was determined in the $<2 \mathrm{~mm}$ size fraction of each topsoil using the sample preparation, X-ray fluorescence spectroscopy and quality control procedures previously described (Allen et al. 2011; Johnson 2011).

\section{Bioaccessible lead}

A sub-set of 50 samples from the urban samples were selected for bioaccessibility testing to cover the range of total $\mathrm{Pb}$ concentrations in the urban sample set. The chosen samples were further sieved to $<250 \mu \mathrm{m}$ as this particle size fraction as this is considered to be the optimum size to adhere to children's hands (Duggan et al. 1985; Calabrese et al. 1997). The total elemental concentration within the $<250 \mu \mathrm{m}$ size fraction was determined using the procedure described above. Assessment of the bioaccessible $\mathrm{Pb}$ was undertaken using the UBM, a gastro-intestinal sequential extraction at physiologically relevant $\mathrm{pHs}$, temperature and timescales to emulate fasting conditions (to provide a conservative estimation) in the human gut. The UBM is based on the method previously described by Oomen et al. (2002), modified to ensure adequate conservatism, robustness and applicability over a range of soil types and different geographical regions, whilst maintaining its physiological relevance (Wragg et al. 2011). Incorporating mouth, stomach and small intestinal phases, the $\mathrm{pH}$ 's used within the test are 6.5, 1.2, 6.3 with extraction times of $60 \mathrm{~s}, 1 \mathrm{~h}, 4 \mathrm{~h}$ respectively. The method generates samples for analysis at the end of the gastric phase extraction, known as 'stomach' and intestinal phase extraction, known as 'stomach and intestine'. Full details of the UBM application to different test soils have been previously described (Broadway et al. 2010; Pelfrene et al. 2011; Roussel et al. 2010; J. Wragg et al. 2009). As a part of its development, which included tightening the $\mathrm{pH}$ requirements of the stomach phase $\mathrm{pH}$ from 1.2-1.5 to 1.2 and a change in the separation step from centrifugation at 3000g for $5 \mathrm{~min}$ to $4500 \mathrm{~g}$ for $15 \mathrm{~min}$, the UBM has 
also been validated against a juvenile swine model for As, $\mathrm{Cd}$ and Pb (Caboche 2009; Denys et al. 2012). The validation study utilised a set of 16 different soils contaminated by mining and smelting activities, including the NIST reference material 2710, resulting in a correlation between relative bioavailable $\mathrm{As}, \mathrm{Cd}$ and $\mathrm{Pb}$ and bioaccessibility that was highly significant for both phases. Denys et al., (2012) showed that the slopes of the regression were not significantly different from 1 (based on 95\% confidence interval) and the regression intercepts were not significantly different from zero.

As there are no standard reference materials available with certified $\mathrm{Pb}$ values from physiologically based bioaccessibility methods, quality control of the extractions was monitored by incorporating the replicate extraction of the BGS guidance material (BGS 102, (Wragg 2009)) into the overall extraction scheme, which had been previously subject to an international inter-laboratory trial (Wragg et al. 2011) generating reference values for comparison. Within every sample batch containing a maximum of 10 unknown samples, one was extracted in duplicate and the rest only once, one blank and one quality control soil were included.

The stomach and intestinal extracts were analysed for their bioaccessible $\mathrm{Pb}$ contents using a Thermo Elemental ExCell quadrupole ICP-MS instrument in combination with a Cetac ASX-510 autosampler. Details of the analysis and instrumental operating conditions have been previously described by Wragg et al., (2011) and Watts et al., (2008) respectively. The measured $\mathrm{Pb}$ concentration in the blank extractions was always less than the calculated method detection limit (five times the average blank measurement ( $\mathrm{n}=7$ ), equating to $3 \mathrm{mg} \mathrm{kg}^{-1}$ ). Bioaccessible $\mathrm{Pb}$ values for BGS $102(\mathrm{n}=8)$ for the gastric phase only, $14.36 \pm 2.43 \mathrm{mg} \mathrm{kg}^{-1}$, were in good agreement with consensus values reported previously (Wragg et al. 2011), $15.2 \pm 6.6 \mathrm{mg} \mathrm{kg}^{-1}$.

The UBM provides gastric and small intestine phase samples. Higher, more conservative, bioaccessible $\mathrm{Pb}$ values which are more reproducible tend to be associated with the gastric phase because of the low $\mathrm{pH}$ conditions employed (Cave et al. 2011; Wragg et al. 2011). As a result the bioaccessible $\mathrm{Pb}$ values associated with the gastric phase of the UBM will be used in further interpretations.

\section{CISED extractions}

The samples investigated for their bioaccessible content were further sub-divided for determination of the solid fractionation of the $\mathrm{Pb}$ content using the CISED method. The selected samples covered the range of bioaccessible $\mathrm{Pb}$ data. Each soil was leached by the CISED sequential extraction using aliquots of de-ionised water and increasing concentrations of (0.01-5.0M) aqua regia in the method detailed by Wragg and Cave (2012). In brief, a $2 \mathrm{~g}$ aliquot of soil was accurately weighed onto the $0.45 \mu \mathrm{m}$ polypropylene filter insert of a Whatman Vectaspin $20 \circledR$ polypropylene centrifuge unit and a $10 \mathrm{ml}$ volume of the initial extractant added. The extractant was passed through the test sample using centrifugal force (3000rpm) and collected for analysis by ICP-AES, and the process repeated with the next volume of extractant. Seven extractants (de-ionised water, $0.01 \mathrm{M}, 0.05 \mathrm{M}, 0.10 \mathrm{M}, 0.50 \mathrm{M}, 1.0 \mathrm{M}$ and $5.0 \mathrm{M}$ aqua regia) were applied to each test soil in duplicate to produce a total of 14 extracts per soil for analysis. For extraction of the latter stages of the CISED (0.1-5.0M) 0.25, 0.50, 0.75 and $1 \mathrm{ml}$ of hydrogen peroxide were added to the extractants making up to volume $(10 \mathrm{ml})$. One sample blank and one sample duplicate were extracted per sample batch. Analysis of the extracts for $\mathrm{Al}, \mathrm{As}, \mathrm{Ca}, \mathrm{Cd}$, $\mathrm{Co}, \mathrm{Cr}, \mathrm{Cu}, \mathrm{Fe}, \mathrm{K}, \mathrm{Li}, \mathrm{Mg}, \mathrm{Mn}, \mathrm{Mo}, \mathrm{Na}, \mathrm{Ni}, \mathrm{P}, \mathrm{Pb}, \mathrm{S}, \mathrm{Se}, \mathrm{Si}, \mathrm{Sr}, \mathrm{V}$ and $\mathrm{Zn}$ was carried out using a Varian Vista AX CCD simultaneous instrument with dedicated Varian SPS-5 Autosampler. The extraction repeatability was $<5 \%$ across all elements analysed; $\mathrm{Pb}$ concentrations were below the method limit of detection for all blank samples.

\section{Chemometric data Analysis}

The Self Modelling Mixture Resolution Algorithm (SMMR) is a multivariate statistical technique that deconvolves two-way data from a multi-component mixture into single components previously described by Cave and co-workers (Cave and Wragg 1997; Cave et al. 2004; Cave 2008). The output from the algorithm is summarised in Fig.3. 


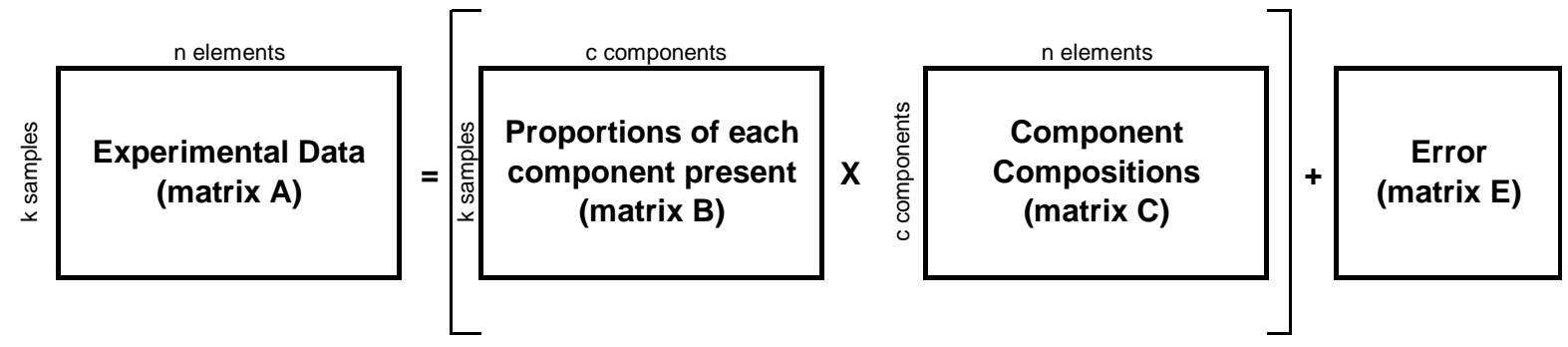

Fig. 3 Diagrammatic representation of the data outputs from the SMMR procedure

\section{Results and Discussion}

\section{Chemometric data Analysis}

The SMMR method was applied to the total element concentration data (matrix A, Fig.3) consisting of 723 samples (276 urban soils and 447 rural soils) and 50 elements and to the CISED extracts data consisting of 10 soils with 14 extracts per soil (140 samples) by 22 elements and was implemented in the MATLAB programming language.

For the total element data the SMMR produces the ISCs and for the CISED extracts the acid soluble physicochemical components. In both instances the $\mathrm{Pb}$ associated with either ISCs or components was determined.
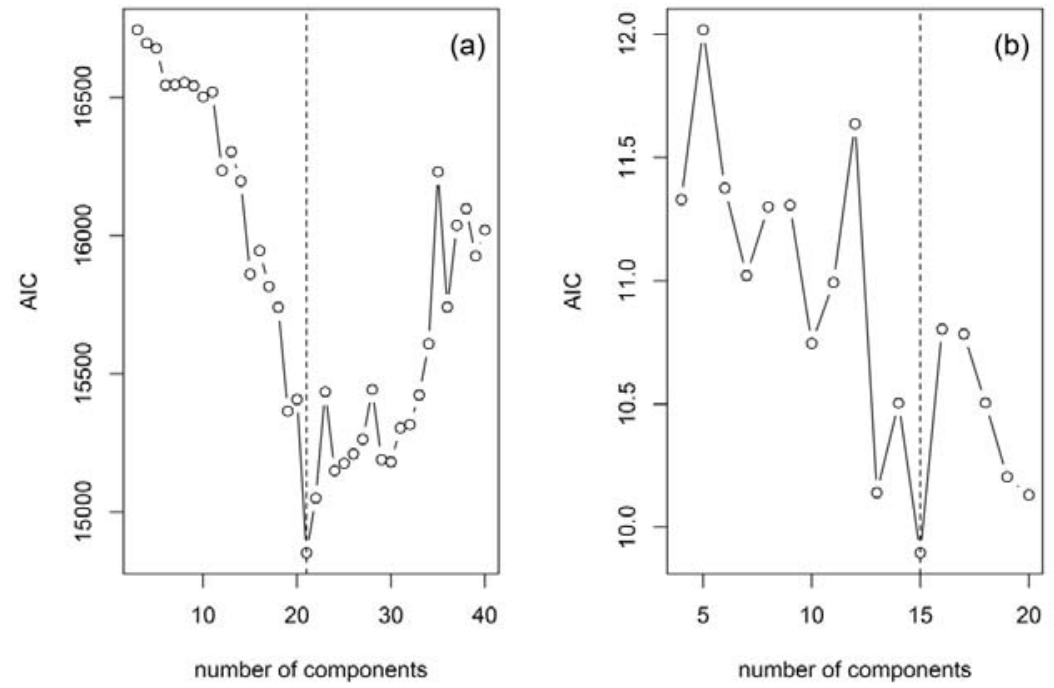

Fig. 4 selection of the number of components for the SMMR model of the total element data a) for total element data and b) CISED extractions

The number of components in the output matrices B and C ( Fig.3) for each of the two data sets was estimated using the minimum Akaike Information Criterion (AIC) (Akaike 1974) as described previously (Wragg and Cave 2012). The AIC provides an objective way of determining which model among a set of models is most parsimonious, i.e. provides the best fit to the data with a minimum number of model parameters. The model with the lowest AIC being chosen as optimum. 
Fig. 4 shows that 21 ISCs were selected for the 723 samples total element data set and 15 components for the CISED extractions of the 10 samples. Multiple linear regression (MLR) modelling, used to examine the relationships between the bioaccessible $\mathrm{Pb}$, the ISCs and components, was carried out using the $\mathrm{R}$ programming language (R Development Core Team 2011).

\section{Pb Fractionation from Total Element data}

The SMMR analysis suggests that 21 geochemically distinct ISCs can be identified. Using the composition and proportions matrices from the SMMR (Fig. 3), the proportion of the $\mathrm{Pb}$ (summed over all 723 samples) associated with each ISC can be calculated. Fig.5 shows the mass of $\mathrm{Pb}$ associated with the 15 ISCs containing the highest mass of $\mathrm{Pb}$. The top eight of these ISCs contain $80 \%$ of the $\mathrm{Pb}$ summed over all samples. In addition to the outputs from the SMMR analysis, the bioaccessible fraction of $\mathrm{Pb}$ in a subset of 50 of the soils from the urban samples is also available. If our receptor of concern is a human and the pathway is by soil ingestion, then establishing a relationship between the $\mathrm{Pb}$ containing ISCs and the bioaccessible fraction of $\mathrm{Pb}$ will provide an insight into the relative mobility of $\mathrm{Pb}$ in the ISCS.

A MLR model was set up with bioaccessible $\mathrm{Pb}$ as the dependant variable and the mass of $\mathrm{Pb}$ associated with each of the 21 ISCs present in each soil (matrix B, Fig.3) as the predictor variables. Using a stepwise selection of predictor parameters with AIC as the selection criteria three ISCs were identified as being significant predictors of bioaccessible Pb (ISC1, ISC4 and ISC7). The final model used a robust MLR model to take into account possible outliers in the data with the confidence intervals (CIs) on the coefficients and the p-values being calculated by bootstrap resampling. The summary statistics for the model are in Table 1 .

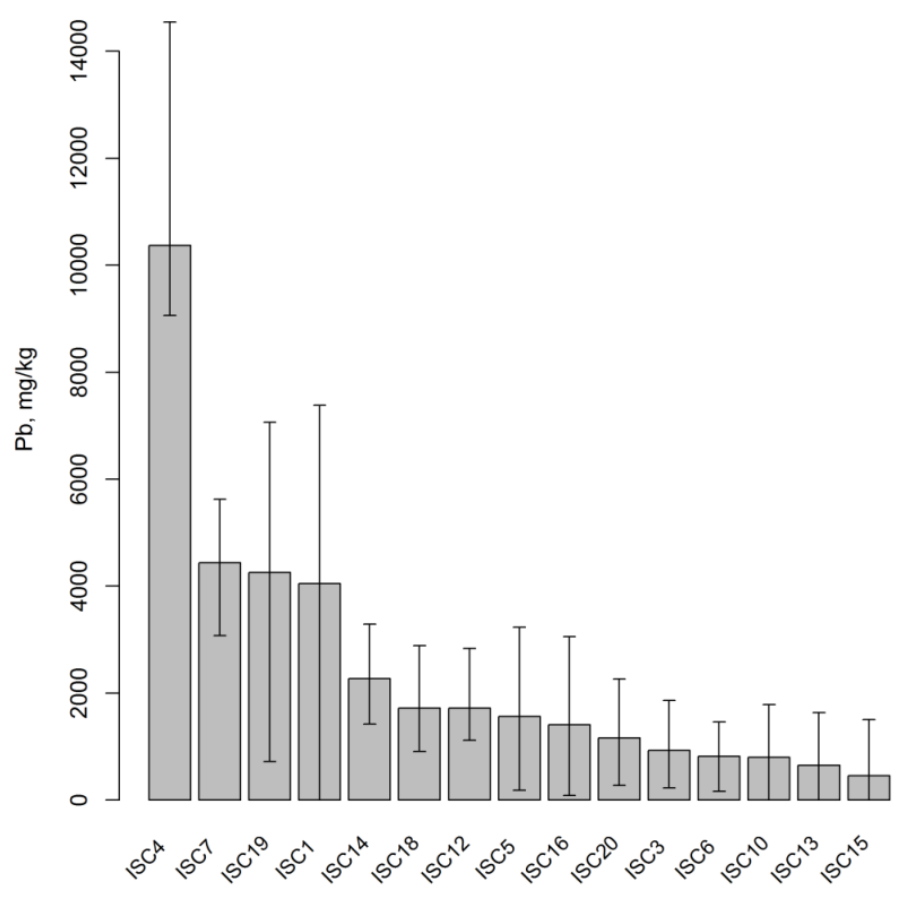

Fig 5. $\mathrm{Pb}$ fractionation in the 15 ISC containing the highest concentration of $\mathrm{Pb}$. Error bars represent $95^{\text {th }}$ percentile confidence limits.

The final MLR model describes $76 \%$ of the variance in the data and suggests that ISCs 1, 4 and 7 contain the bioaccessible $\mathrm{Pb}$ in the soil samples. All three ISCs are in the top four Pb containing ISCS for total Pb (Fig.5). Although ISC 19 is also in the top $4 \mathrm{~Pb}$ containing ISCs it is not found to be a predictor of bioaccessible $\mathrm{Pb}$ leading to the conclusion that the $\mathrm{Pb}$ in this ISC is not bioaccessible. 
Table 1 Summary statistics for the MLR model used to predict Pb bioacessibility from ISC Pb values

\begin{tabular}{|c|c|c|c|c|}
\hline Coefficients: & & \multicolumn{2}{|c|}{ 95th percentile CI } & \\
\hline & Value & low & High & p-value \\
\hline (Intercept) & 0.99 & -9.28 & 10.34 & 0.343 \\
\hline ISC1 & 1.00 & 0.08 & 1.83 & 0.017 \\
\hline ISC4 & 0.57 & 0.41 & 0.90 & $<0.001$ \\
\hline ISC7 & 1.65 & 0.61 & 2.80 & 0.001 \\
\hline & & & & \\
\hline r-square & 0.76 & & & \\
\hline
\end{tabular}

Examination of the coefficients of the model shows that the intercept is not significantly different from zero suggesting that all of the bioaccessible $\mathrm{Pb}$ can be accounted for by the total element data ISCs and no other constant term is required. ISCs 1,4 and 7 , can contribute a fraction of their Pb content between 0 and a maximum of 1 (zero being no contribution and 1 indicating all the $\mathrm{Pb}$ in that component is bioaccessible). Table 1 shows that the coefficients for ISC1 and ISC7 are close to 1 (within uncertainty limits) and that ISC4 is less than 1 (ca.0.6). This suggests that all of the Pb associated with ISC1 and ISC7 is bioaccessible and that a smaller fraction of the $\mathrm{Pb}$ in ISC4 contributes to the total bioaccessible fraction.
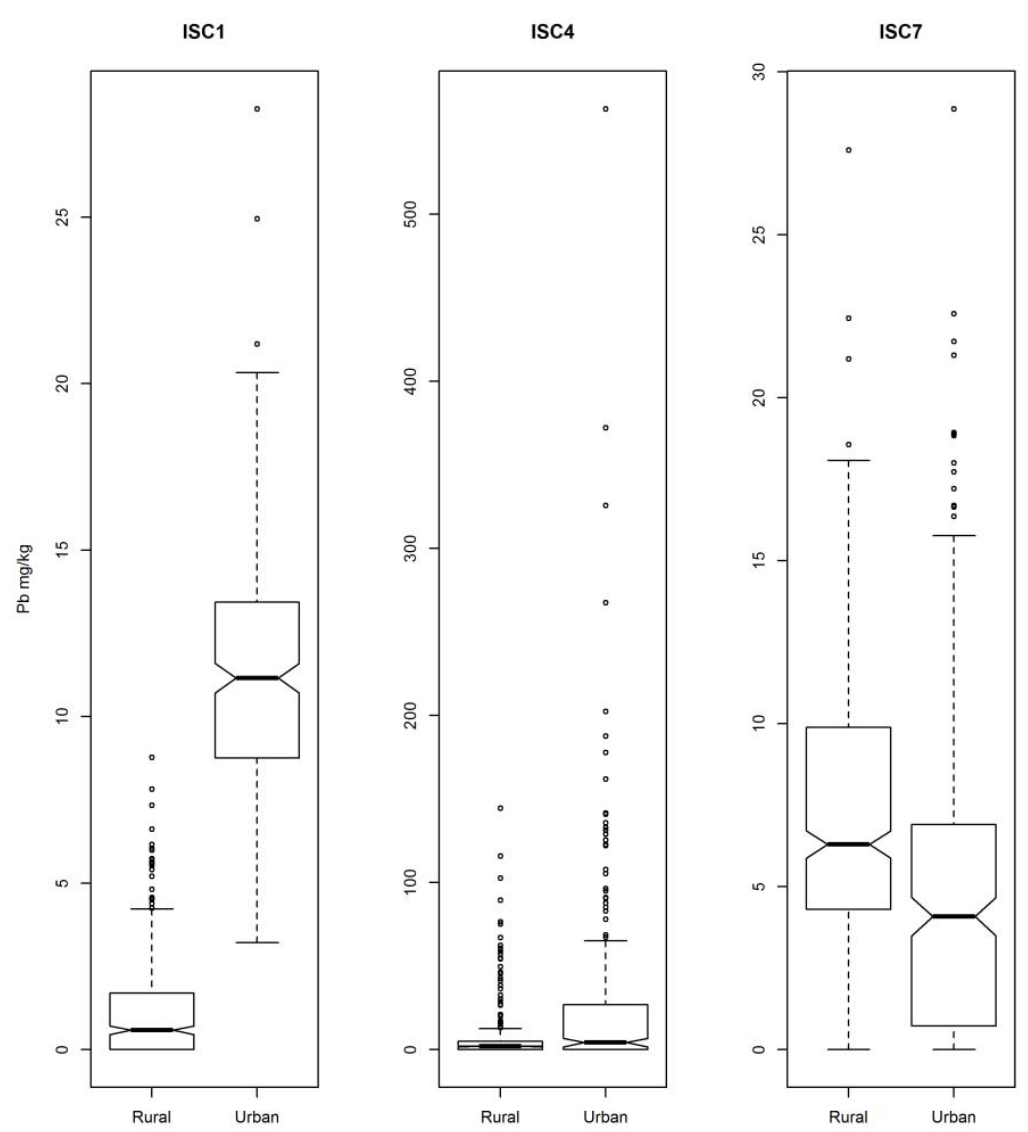

Fig. 6 Boxplots of the $\mathrm{Pb}$ associated with ISCs 1, 4 and 7 split into rural and urban populations. The centre line of the box is the median and the open circles are points greater than 3 times the interquartile range distant from the median. 
The contributions to the $\mathrm{Pb}$ content of the soils of these three ISCs split into those from the rural and the urban areas are shown as box and whisker plots in Fig. 6. If there are higher concentrations of $\mathrm{Pb}$ for a particular ISC in a soil for a particular category then this implies there is a higher amount of that ISC in the soil sample. For example the $\mathrm{Pb}$ contribution for ISC 1 is higher in the urban samples than rural samples and therefore the amount of ISC 1 in urban samples is higher than the rural samples.

Fig. 6 shows that ISCs 1 and 4 have higher concentrations of $\mathrm{Pb}$ in the samples found in the urban environment whereas ISC 7 shows the opposite trend. ISCS 1 and 7 cover similar concentration ranges ( 0 to $30 \mathrm{mg} \mathrm{kg}^{-1} \mathrm{~Pb}$ ) whereas ISC4 has concentrations of Pb up to $563 \mathrm{mg} \mathrm{kg}^{-1}$.

Fig.s 7 to 9 show the chemical element compositions of the three ISCs set out in decreasing order of percentage contribution. The error bars represent the 95th percentile confidence limits.

In ISC1 (Fig. 7) the most abundant element is Fe (ca.40\%) with $\mathrm{Al}$ (ca. 20\%), Ca (ca. $10 \%$ ) and P (ca. 2\%) the median $\mathrm{Pb}$ content for this ISC is ca.0.04\% but the uncertainty shows that this is quite variable. ISC1 also contains V, Cr, Zn and $\mathrm{Cu}$ at similar concentrations and Fig. 6 shows that it is more prevalent in the urban soils. This suggest that this may be an iron oxyhydroxide which are known be impure, able to adsorb metals (Cornell and Schwertmann 1996) and can be formed through anthropogenic processes.

ISC4 (Fig. 8) is 50\% Ca; Fe and $\mathrm{Al}$ are not well defined but $\mathrm{P}$ and $\mathrm{Mg}$ are ca. 5\%. Pb makes up about $1 \%$ of this ISC and also contains similar compositions of $\mathrm{Cr}$, Zn, $\mathrm{Cu}$ and a smaller but significant concentration of Sn. This ISC is again more prevalent in the urban environment and accounts for the largest proportion of the total $\mathrm{Pb}$ values $>30 \mathrm{mg} \mathrm{kg}^{-1}$ (Fig 6). The high Ca content could point to this being a carbonate phase but if this were the case it would be expected that the carbonate would be fully soluble in the acid environment of the UBM test and $\mathrm{Pb}$ would be fully bioaccessible. The regression analysis (Table 1) suggests that this is not the case. The high concentration of P (ca. 10\%) could suggest a phosphate mineral (Fig. 8) but there is also evidence that Ca can form organo-mineral assemblages (Chen et al. 2014) in soil but the exact nature of ISC 4 cannot be clearly defined without further mineral specific studies. Despite this, the fact that it is more prevalent in in the urban environment suggests it is formed from anthropogenic processes possibly derived from aerial deposition of air particulates.
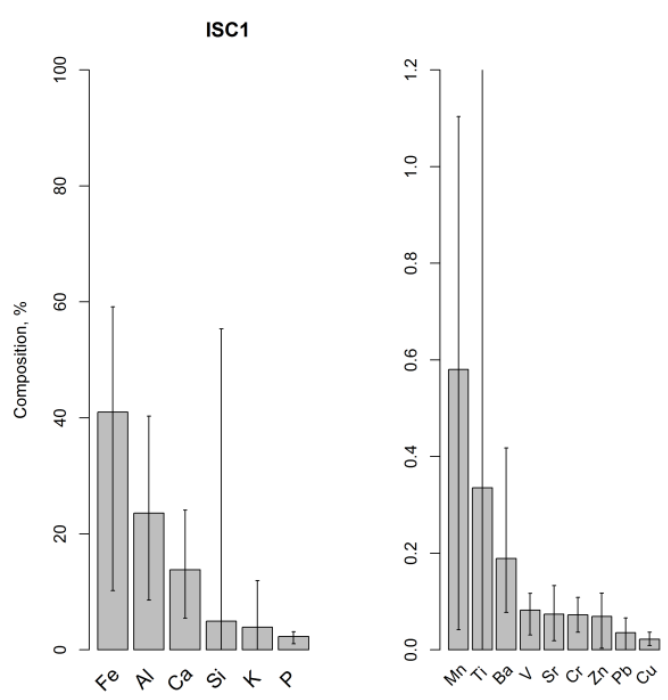

Fig. 7 Chemical element composition of ISC1 

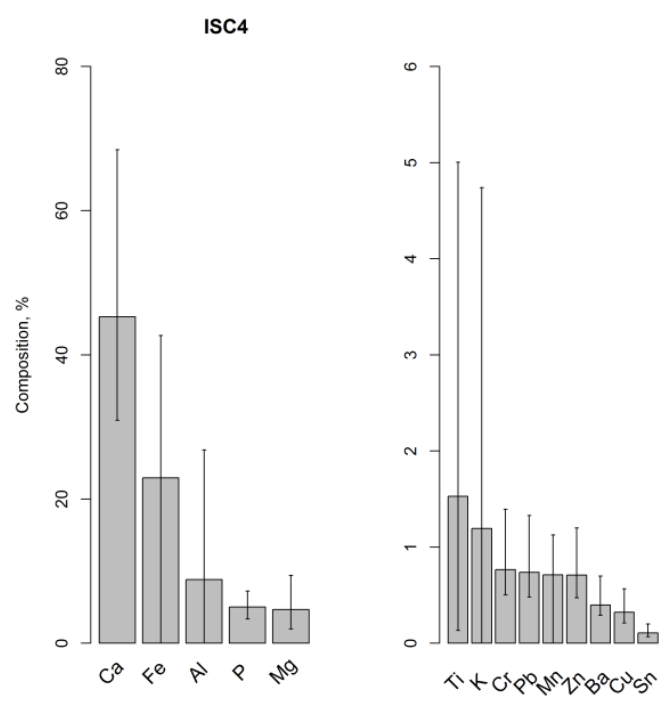

Fig. 8 Chemical element composition of ISC4

ISC7 (Fig. 9) is predominantly $\mathrm{Si}$ (ca. 80\%) with the next most abundant element being Ca (ca. 10\%). The high $\mathrm{Si}$ to Ca ratio suggests that rather than being a $\mathrm{Ca} / \mathrm{Si}$ mineral that this is more likely to be a quartz material with carbonate coatings. Further evidence for this comes from the regression of bioaccessible $\mathrm{Pb}$ against the $\mathrm{Pb}$ content of the ISCs (Table 4) which shows the Pb associated with ISC 7 is fully bioaccessible. The fact that the $\mathrm{Pb}$ in this ISC is fully bioaccessible $\mathrm{Pb}$ suggests that it will be associated with carbonate coatings rather than the more recalcitrant quartz material. The $\mathrm{Pb}$ content is ca. $0.1 \%$ with similar concentrations of $\mathrm{Zn} \mathrm{Cu}$ and $\mathrm{Cr}$. Unlike ISCs 1 and 4 there appear to be generally higher concentrations of this ISC in the rural samples (Fig. 6).
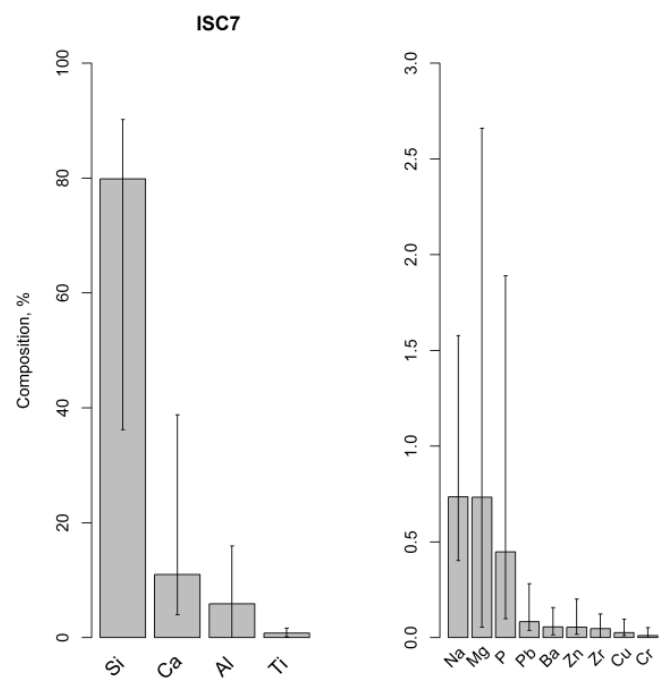

Fig. 9 Chemical element composition of ISC7

The MLR modelling of bioaccessible Pb using the ISC data demonstrates that the ISCs derived from SMMR modelling of the total element data can be quantitatively linked to the bioaccessible fraction in the soils and that the three ISCs associated with bioaccessible $\mathrm{Pb}$ have plausible chemical signatures that can be linked back to specific physico-chemical components in the soil. 


\section{Pb Fractionation from the CISED sequential extraction procedure}

The CISED sequential extraction identified 15 distinct geochemical components (Fig. 4(b)). The distribution of $\mathrm{Pb}$ between each of these components containing the highest concentration of $\mathrm{Pb}$ is shown in Fig. 10 with the majority of the $\mathrm{Pb}$ being associated with one component (component 3). The mass of each of the components extracted over the 14 extraction steps was summed for each sample to give a data set of 10 samples by 14 extracts.

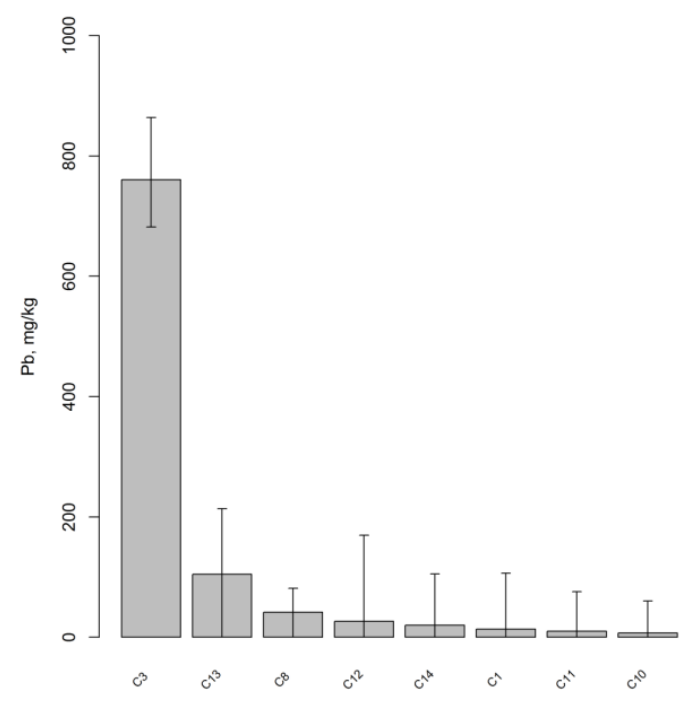

Fig. $10 \mathrm{~Pb}$ fractionation in the 8 components containing the highest concentration of $\mathrm{Pb}$. Error bars represent $95^{\text {th }}$ percentile confidence limits.

In a similar manner to the total element data, a MLR regression model was set up with the Pb content of the 15 components in each sample as the predictor variables and the bioaccessible fraction as the dependant variable. Using the same variable selection criteria used for the ISCs model, only one CISED component was shown to be significant in predicting the bioaccessible fraction (component 3). Pearson correlation coefficients between CISED component 3 and the equivalent 10 samples from the total element data ISCs, picks out the three ISCs that were identified as being controlling factors for bioaccessible $\mathrm{Pb}$ (Table 1) as having the highest positive correlations (ISC4 0.993, ISC7 0.941 and ISC1 0.722) showing a strong link between the ISCs and CISED component.

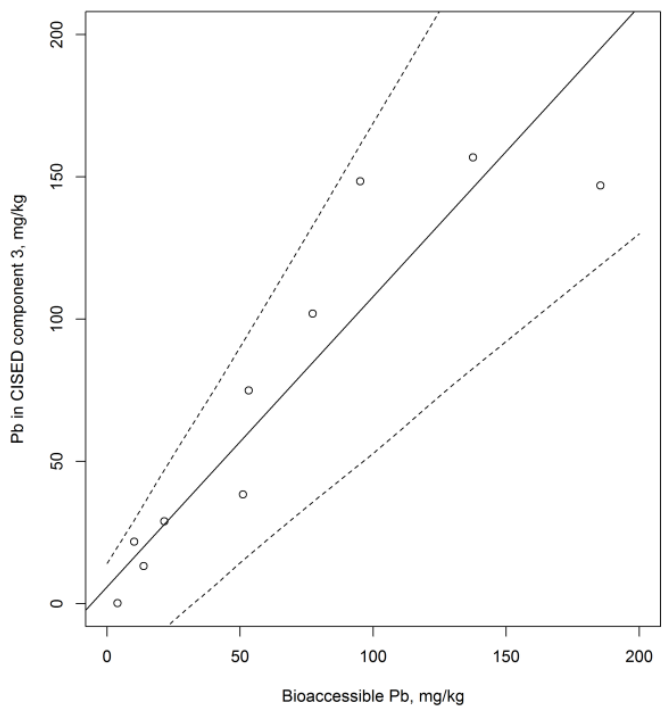

Fig. 11 Regression line and bootstrapped $95^{\text {th }}$ percentile confidence limits showing the relationship between bioaccessible $\mathrm{Pb}$ and the lead content of CISED component 3 
A linear regression of bioaccessible $\mathrm{Pb}$ against the $\mathrm{Pb}$ associated with component 3 (using orthogonal regression as both measures have similar uncertainties) and bootstrapping to determine the $\mathrm{CI}$ on the regression line leads to a slope of 1.02 (95 ${ }^{\text {th }}$ percentile CI 0.76 to 1.59$)$ and an intercept of $5.93\left(95^{\text {th }}\right.$ percentile CI -14.1 to 26.2$)$ suggesting that the bioaccessible $\mathrm{Pb}$ as measured by the UBM is almost entirely accounted for by the $\mathrm{Pb}$ associated with CISED component 3 (Fig. 11). Examination of the chemical composition of component 3 (Fig.12) shows that the error bars for $\mathrm{Al}, \mathrm{Fe}$ and $\mathrm{Ca}$ are all large and therefore their contribution to component 3 is not well defined. $\mathrm{P}$ and $\mathrm{Pb}$, however, are shown to be present (ca.10-20\%) as well as $\mathrm{Cu}$ and $\mathrm{Ba}$ (ca. 2\%).

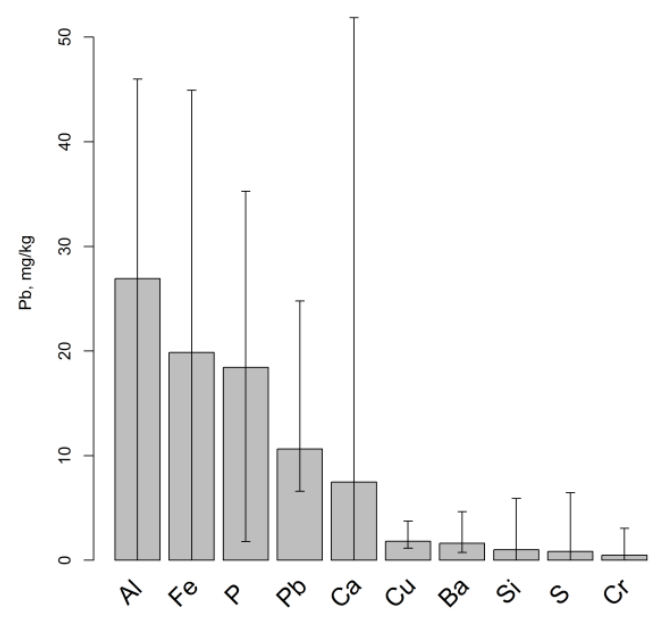

Fig. 12 Chemical element composition of CISED component 3

The fractionation of $\mathrm{Pb}$ from the ISC study of the total element data suggests that at least two of the ISCs (ISCs 4 and 7) related to bioaccessible $\mathrm{Pb}$ are Ca rich and one of these (ISC 7) may be associated with carbonates (Fig.7 and fig.8).

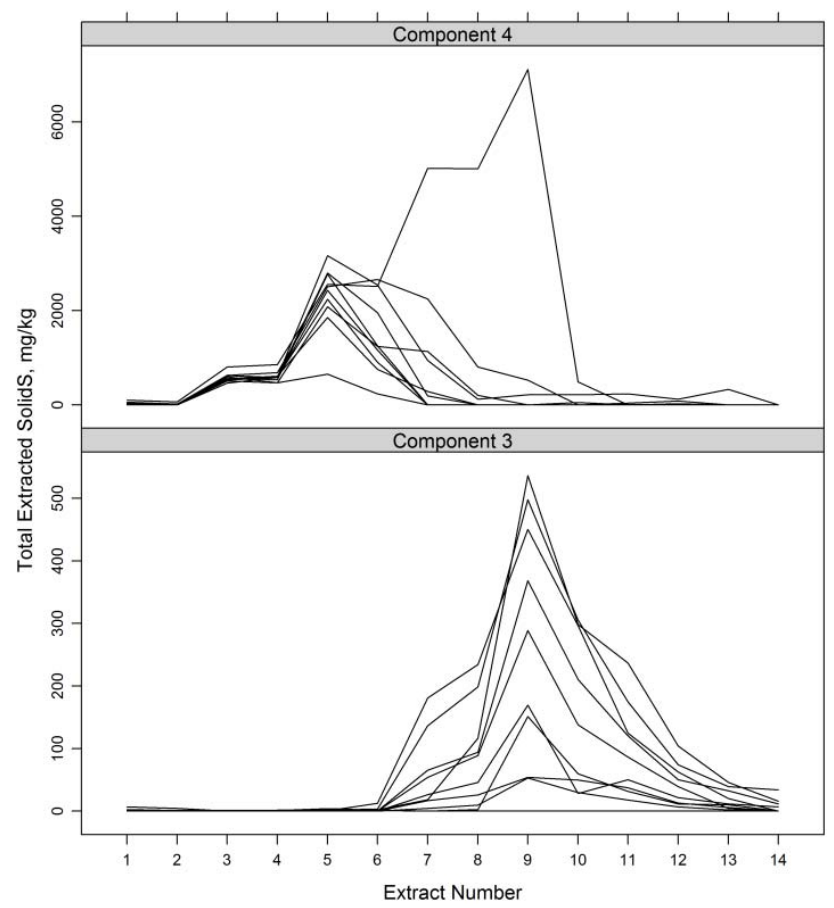

Fig. 13 CISED extraction profiles for the calcium carbonate component (Component 4) and the component associated with bioaccessible $\mathrm{Pb}$ (Component 3) for the CISED extractions on the 10 soil samples 
Fig.13 shows the CISED extraction profiles for the subset of 10 samples, showing the 14 extraction points associated with the application of the increasing acid strength in the method, for components 3 and 4 . Component 4 accounts the majority of the Ca found in the samples and is thought to be a calcium carbonate component. Clearly, component 3 has an extraction window at higher acid strengths (extract 7 to 12 peaking at extract 8) than the extraction window for calcium carbonate (extract 3 to 10 peaking at extract 5) suggesting that component 3 is not a simple carbonate. The sample showing an anomalous extraction profile for component 4 has higher carbonate content than the other samples and therefore requires higher acid strength to dissolve it from the soil.

A possible explanation for component 3 comes from literature studies in which a number of research groups show that $\mathrm{Pb}$ derived from anthropogenic sources where significant concentrations of $\mathrm{P}$ also exist results in a relatively stable form in soils as chloropyromorphite $\left(\mathrm{Pb}_{5}\left(\mathrm{PO}_{4}\right)_{3} \mathrm{Cl}\right)$ or similar pyromorphite minerals (Hettiarachchi and Pierzynski 2004; Cotter-Howells et al. 1994; Scheckel et al. 2005). In particular, this mineral can be found in a specific form in Ca rich environments where $\mathrm{Ca}$ can replace $\mathrm{Pb}$ to form chloroapatite $\left[\mathrm{Ca}_{5}\left(\mathrm{PO}_{4}\right)_{3} \mathrm{Cl}\right](\mathrm{Cotter}-\mathrm{Howells}$ et al. 1994). This is in agreement with the composition of component 3 which clearly contains $\mathrm{Pb}, \mathrm{P}$ and possibly $\mathrm{Ca}$ (Fig. 12). All three of the ISCs associated with bioaccessible $\mathrm{Pb}$ contain $\mathrm{P}, \mathrm{Pb}$ and $\mathrm{Ca}$ (Figs 7-9) suggesting that fine grained pyromorphite is formed within each of these ISCs. This would also explain why the CISED only identifies one component (the pyromorphite) whereas the ISC study showed there were three components. This suggests the three ISCs all contain fine grained pyromorphite which is extracted as one common component by the CISED procedure. It could be speculated that the three ISCs have been formed recently and have trapped the anthropogenic $\mathrm{Pb}$ in the form of the pyromorphite mineral. Some studies suggest that $\mathrm{Pb}$, in the form of a pyromorphite mineral, is relatively stable and not bioaccessible (Hettiarachchi and Pierzynski 2004; Scheckel et al. 2005). Other studies, however, have shown that pyromorphite solubility is increased in the low $\mathrm{pH}$ environment found in the stomach compartment (Xie and Giamar 2007; Tang et al. 2004) and that the presence of impurities and organic acids also increases its solubility (Debela et al. 2010; Xie and Giamar, 2007). This study shows, however, that if the assumption that pyromorphite is being formed is correct, that this mineral forms the majority of the bioaccessible $\mathrm{Pb}$ fraction as measured by the UBM bioaccessibility method for the samples studied here. Further mineral specific investigation of the soils is required to confirm these findings.

\section{Conclusions}

The study specifically shows that SMMR modelling of total element data from a regional geochemical survey provides meaningful fractionation information on the total $\mathrm{Pb}$ content of the soils in terms of ISCs. This data can be quantitatively linked to bioaccessibility measurements allowing the identification of the ISCs which contain the bioaccessible $\mathrm{Pb}$ fraction. Comparison of the ISCs with physico-chemical components derived from the CISED sequential extraction method shows that there are distinct differences between the two methods. The latter method only targets the more labile acid soluble fractions whereas the former reflects all forms of $\mathrm{Pb}$ regardless of their mobility. Quantitative linkages, however, between the CISED components, bioaccessible Pb and the total element data ISCs has led to a synergistic understanding of the geochemistry of the bioaccessible $\mathrm{Pb}$ over the region being studied.

This outcome suggests that SMMR modelling of ISCs combined with sequential extraction fractionation of a subset of soils using the CISED method can provide a powerful tool for studying the fractionation of PHE in soils on a regional scale.

\section{Acknowledgments}

This work is published with permission of the Executive Director of the British Geological Survey. 


\section{References}

Abollino, O., Malandrino, M., Giacomino, A., \& Mentasti, E. (2011). The role of chemometrics in single and sequential extraction assays: A review: Part I. Extraction procedures, uni- and bivariate techniques and multivariate variable reduction techniques for pattern recognition. Analytica Chimica Acta, 688(2), 104-121, doi:10.1016/j.aca.2010.12.020.

Akaike, H. (1974). A new look at the statistical model identification. IEEE Transactions on Automatic Control, 19(6), 716-723.

Allen, M. A., Cave, M. R., Chenery, S. R. N., Gowing, C. J. B., \& Reeder, S. (2011). Sample Preparation and Inorganic Analysis for Urban Geochemical Survey Soil and Sediment Samples. In Mapping the Chemical Environment of Urban Areas (pp. 28-46): John Wiley \& Sons, Ltd.

Ander, E. L., Johnson, C. C., Cave, M. R., Palumbo-Roe, B., Nathanail, C. P., \& Lark, R. M. (2013). Methodology for the determination of normal background concentrations of contaminants in English soil. Science of the Total Environment, 454-455(0), 604-618, doi:http://dx.doi.org/10.1016/j.scitotenv.2013.03.005.

Bacon, J. R., \& Davidson, C. M. (2008). Is there a future for sequential chemical extraction? Analyst, 133, 2546.

Broadway, A., Cave, M. R., Wragg, J., Fordyce, F. M., Bewley, R. J. F., Graham, M. C., et al. (2010). Determination of the bioaccessibility of chromium in Glasgow soil and the implications for human health risk assessment Science of the Total Environment, 409, 267-277, doi:doi:10.1016/j.scitotenv.2010.09.007

Caboche, J. (2009). Validation d'un test de mesure de bioaccessibilité. Application à quatre éléments traces métallique dans les sols: As, $\mathrm{Cd}, \mathrm{Pb}$ et $\mathrm{Sb}$. L’Institut National Polytechnique de Lorraine, Nancy.

Calabrese, E. J., Stanek, E. J., \& Barnes, R. (1997). Soil ingestion rates in children identified by parental observation as likely high soil ingesters. Journal of Soil Contamination, 6(3), 271-279.

Cave, M. (2008). The use of self modelling mixture resolution methods for the interpretation of geochemical data sets British Geological Survey.

Cave, M. R., Milodowski, A. E., \& Friel, E. N. (2004). Evaluation of a method for Identification of Host Physico-chemical Phases for Trace Metals and Measurement of their Solid-Phase Partitioning in Soil Samples by Nitric Acid Extraction and Chemometric Mixture Resolution. Geochemistry: Exploration, Environment, Analysis, 4, 71-86.

Cave, M. R., \& Wragg, J. (1997). Measurement of trace element distributions in soils and sediments using sequential leach data and a non-specific extraction system with chemometric data processing. Analyst, 122(11), 1211-1221.

Cave, M. R., Wragg, J., Denys, S., Jondreville, C., \& Feidt, C. (2011). Oral Bioavailability. In F. Swartjes (Ed.), Dealing with Contaminated Sites: From Theory towards Practical Application: Springer.

Cave, M. R., Wragg, J., \& Harrison, H. (2013). Measurement modelling and mapping of arsenic bioaccessibility in Northampton, UK. Journal of Environmental Science \& Health Part A, 48(6), 629-640.

Chen, C., Dynes, J. J., Wang, J., Karunakaran, C., \& Sparks, D. L. (2014). Soft X-ray Spectronnicroscopy Study of Mineral-Organic Matter Associations in Pasture Soil Clay Fractions. Environmental Science \& Technology, 48(12), 6678-6686, doi:10.1021/es405485a.

Cornell, R. M., \& Schwertmann, U. (1996). The Iron Oxides - Structure Properties, Reactions, occurences and Uses. Weinheim: VCH Publishers.

Cotter-Howells, J. D., Champness, P. E., Charnocky, J. M., \& Pattrick, R. A. D. (1994). Identification of pyromorphite in mine-waste contaminated soils by ATEM and EXAFS. European Journal of Soil Science, 45(4), 393-402, doi:10.1111/j.1365-2389.1994.tb00524.x.

Debela, F., Arocena, J. M., Thring, R. W., \& Whitcombe, T. (2010). Organic acid-induced release of lead from pyromorphite and its relevance to reclamation of Pb-contaminated soils. Chemosphere, 80(4), 450-456, doi:10.1016/j.chemosphere.2010.04.025.

Denys, S., Caboche, J., Tack, K., Rychen, G., Wragg, J., Cave, M., et al. (2012). In Vivo Validation of the Unified BARGE Method to Assess the Bioaccessibility of Arsenic, Antimony, Cadmium, and Lead in Soils. Environmental Science \& Technology, 46, 6252-6260, doi:10.1021/es3006942.

Duggan, M. J., Inskip, M. J., Rundle, S. A., \& Moorcroft, J. S. (1985). Lead in Playground Dust and on the Hands of Schoolchildren. Science of the Total Environment, 44(1), 65-79.

Flight, D. M. A., \& Scheib, A. J. (2011). Soil Geochemical Baselines in UK Urban centres: The G-BASE Project. In C. Johnson, A. Demetriades, J. Locutura, \& R. T. Ottesen (Eds.), Mapping the Chemical Environment of Urban Areas (pp. 186-206). Oxford: Wiley-Blackwell.

Hettiarachchi, G. M., \& Pierzynski, G. M. (2004). Soil lead bioavailability and in situ remediation of leadcontaminated soils: A review. Environmental Progress, 23(1), 78-93, doi:10.1002/ep.10004. 
Johnson, C. C. (2011). Understanding the Quality of Chemical Data from the Urban Environment - Part 1: Quality Control Procedures. In C. C. Johnson, A. Demetriades, J. Locutura, \& R. T. Ottesen (Eds.), Mapping the Chemical Environment of Urban Areas (pp. 61-76). Oxford: Wiley-Blackwell.

Johnson, C. C., Breward, N., Ander, E. L., \& Ault, L. (2005). G-BASE: Baseline geochemical mapping of Great Britain and Northern Ireland. Geochemistry: Exploration, Environment, Analysis, 5(4), 347-357.

Oomen, A. G., Hack, A., Minekus, M., Zeijdner, E., Cornelis, C., Schoeters, G., et al. (2002). Comparison of five in vitro digestion models to study the bioaccessibility of soil contaminants. Environmental Science \& Technology, 36(15), 3326-3334.

Pelfrene , A., Waterlot, C., Mazzuca, M., Nisse, C., Bidar, G., \& Francis, D. (2011). Assessing Cd, Pb, Zn human bioaccessibility in smeltercontaminated agricultural topsoils (northern France). Environmental Geochemistry and Health, 33, 477-493.

R Development Core Team (2011). R: A language and environment for statistical computing. Vienna, Austria.: R Foundation for Statistical Computing.

Roussel, H., Waterlot, C., Pelfrene, A., Pruvot, C., Mazzuca, M., \& Douay, F. (2010). Cd, Pb and Zn oral bioaccessibility of urban soils contaminated in the past by atmospheric emissions from two lead and zinc smelters. Arch Environ Contam Toxicol, 58(4), 945-954.

Scheckel, K. G., Ryan, J. A., Allen, D., \& Lescano, N. V. (2005). Determining speciation of Pb in phosphateamended soils: Method limitations. Science of the Total Environment, 350(1-3), 261-272, doi:http://dx.doi.org/10.1016/j.scitotenv.2005.01.020.

Tang, X. Y., Zhu, Y. G., Chen, S. B., Tang, L. L., \& Chen, X. P. (2004). Assessment of the effectiveness of different phosphorus fertilizers to remediate $\mathrm{Pb}$-contaminated soil using in vitro test. Environment International, 30(4), 531-537, doi:10.1016/j.envint.2003.10.008.

Watts, M. J., Button, M., Brewer, T. S. D., Jenkin, G. R. T., \& Harrington, C. F. (2008). Quantitative arsenic speciation in two species of earthworms from a former mini site. Journal of Environmental Monitoring, 10, 753-759.

Wragg, J. (2009). BGS Guidance Material 102, Ironstone Soil, Certificate of Analysis. British Geological Survey

Wragg, J., Cave, M., \& Nathanail, P. (2007). A Study of the relationship between arsenic bioaccessibility and its solid-phase distribution in soils from Wellingborough, UK. Journal of Environmental Science and Health Part A, 42(9), 1303 - 1315.

Wragg, J., Cave, M., Taylor, H., Basta, N., Brandon, E., Casteel, S., et al. (2009). Interlaboratory Trial of a Unified Bioaccessibility Procedure. Open. Nottingham: British Geological Survey.

Wragg, J., \& Cave, M. R. (2012). Assessment of a geochemical extraction procedure to determine the solid phase fractionation and bioaccessibility of potentially harmful elements in soils: A case study using the NIST 2710 reference soil. Analytica Chimica Acta, 722(0), 43-54, doi:10.1016/j.aca.2012.02.008.

Wragg, J., Cave, M. R., Basta, N., Brandon, E., Casteel, S., Denys, S. e. b., et al. (2011). An Inter-laboratory Trial of the Unified BARGE Bioaccessibility Method for Arsenic, Cadmium and Lead in Soil. Science of the Total Environment, 409, 4016-4030.

Xie, L., \& Giammar, D. E. (2007). Equilibrium solubility and dissolution rate of the lead phosphate chloropyromorphite. Environmental Science \& Technology, 41(23), 8050-8055, doi:10.1021/es071517e. 